\title{
Comment on: COVID-19 and abortion right
}

\author{
Seyyed Javad Madani, MD, PhD Candidate ${ }^{1,2}$, Mohammad Mohammadi, MD, MPH, PhD \\ ${ }^{1}$ Medical Ethics and History of Medicine Research Center, Tehran University of Medical Sciences, Tehran; ${ }^{2}$ Department of Medical Ethics, Faculty \\ of Medicine, Mazandaran University of Medical Sciences, Sari; ${ }^{3}$ Department of Medical Ethics, School of Medicine Mashhad University of Medical \\ Sciences, Mashhad, Iran
}

We read with great interest the article "COVID-19 and the right to abortion" written by Rashidpouraie and Sharifi [1]. This article briefly introduces the reasons for abortion and considers the occurrence or fear of developing COVID-19 as one of the reasons for attempting an abortion. To prevent the complications of unsafe abortions, it recommends providing safe abortion conditions for pregnant women with COVID-19. This article uses maternal autonomy and the unknown effects of this disease on the mother and fetus as a reason for justifying abortion.

According to the available information, pregnant women do not contract this infection more frequently than the general population. In addition, most experience mild or moderate disease [2]. The most common symptoms in pregnant women are fever and cough [3]. Severe illness, including the need for hospitalization in the intensive care unit, is relatively uncommon in young women of childbearing age [4]. However, some reports suggest that pregnant women are at an increased risk of severe illness if they are infected with viruses from the same family as SARS-CoV-2 and other respiratory viruses, such as influenza [5]. Therefore, it is possible for pregnant women with COVID-19 to potentially have more severe symptoms such as pneumonia and hypoxia. However, according to the largest systematic review, the risk of death from COVID-19 is not increased [2].

Intrauterine transmission of COVID-19 from a pregnant woman to her fetus is unlikely [5]. Regarding the effect on the fetus, despite more than 31 million confirmed COVID-19 infections, no significant increase in the incidence of congenital malformations has been reported. In a systematic review of PregCOV-19 life, there was no evidence of an increase in stillbirth or neonatal mortality in women with COVID-19 [3]. There is also no evidence that fetal growth restriction results from COVID-19 [2].

The only negative effect of COVID-19 in pregnant women is an almost threefold increase in the risk of preterm delivery, most of which is iatrogenic and occurs at an average of 38 weeks [4]. According to all the points mentioned, having COVID-19 is not a valid reason for abortion because of its lack of a serious negative effect on the health of the fetus and mother and because attempting an abortion does not have a positive effect on the recovery of the infected mother. Regardless of whether abortion is banned in the country, it does not create a special right for a pregnant mother with COVID-19 that is not shared by healthy pregnant women.

\section{Conflict of interest}

No potential conflict of interest relevant to this article was reported.

\section{Ethical approval}

This study does not require approval of the Institutional Review Board because no patient data is contained in this article.

Received: 2021.02.15. Revised: 2021.02.22. Accepted: 2021.02.23. Corresponding author: Seyyed Javad Madani, MD, PhD Candidate Medical Ethics and History of Medicine Research Center, 16 Azar St., Keshavarz Blvd., Tehran, Iran

E-mail: j.madani@mazums.ac.ir

https://orcid.org/0000-0002-0991-3274

Articles published in Obstet Gynecol Sci are open-access, distributed under the terms of the Creative Commons Attribution Non-Commercial License (http://creativecommons org/licenses/by-nc/3.0/) which permits unrestricted non-commercial use, distribution, and reproduction in any medium, provided the original work is properly cited.

Copyright $\odot 2021$ Korean Society of Obstetrics and Gynecology 


\section{Obstetrics \& Gynecology Science}

Vol. 64, No. 3, 2021

\section{Patient consent}

Written informed consent and the use of images from patients are not required for the publication.

\section{Funding information}

None.

\section{References}

1. Rashidpouraie R, Sharifi MN. COVID-19 and abortion right. Obstet Gynecol Sci 2020;63:743-44.

2. Royal College of Obstetricians and Gynaecologists, Royal College of Midwives and Royal College of Paediatrics and Child Health, with input from the Royal College of Anaesthetists, the Obstetric Anaesthetists' Association, Public Health England and Public Health Scotland. Coronavirus (COVID-19) infection and pregnancy - guidance for healthcare professionals: Version 13 - 19 February 2021 [Internet]. London (UK): Royal College of Obstetri- cians and Gynaecologists; c2021 [cited 2021 Feb 22]. Available from: https://www.rcog.org.uk/globalassets/ documents/guidelines/2021-02-19-coronavirus-covid19-infection-in-pregnancy-v13.pdf.

3. Allotey J, Stallings E, Bonet M, Yap M, Chatterjee S, Kew $T$, et al. Clinical manifestations, risk factors, and maternal and perinatal outcomes of coronavirus disease 2019 in pregnancy: living systematic review and meta-analysis. BMJ 2020;370:m3320.

4. Knight M, Bunch K, Vousden N, Morris E, Simpson N, Gale $C$, et al. Characteristics and outcomes of pregnant women admitted to hospital with confirmed SARSCoV-2 infection in UK: national population based cohort study. BMJ 2020;369:m2107.

5. Centers for Disease Control and Prevention. Coronavirus Disease (COVID-19). People who need extra precautions: pregnancy and breastfeeding. Pregnancy, breastfeeding, and caring for newborns. [Internet]. Washington, DC (US): Centers for Disease Control and Prevention, c2020 [2020 Dec 28]. Available from: https://www.cdc.gov/ coronavirus/2019-ncov/need-extra-precautions/pregnancy-breastfeeding.html. 